\title{
COMMISSIONING OF THE HELIUM REFRIGERATION SYSTEM FOR THE COMPACT MUON SOLENOID (CMS) DETECTOR OF LHC
}

\author{
G. Perinic and T. Dupont
}

At CERN a new helium refrigeration plant specified for a cooling capacity of $800 \mathrm{~W}$ at $4.45 \mathrm{~K}$, $4500 \mathrm{~W}$ between $60 \mathrm{~K}$ and $80 \mathrm{~K}$ and $4 \mathrm{~g} / \mathrm{s}$ liquefaction simultaneously has been installed and commissioned. In a first operation phase, the plant will provide the refrigeration capacity for the cool down and the operation of the superconducting solenoid of the CMS experiment during the magnet tests at the surface of the LHC interaction point 5. On completion of the tests a part of the refrigeration plant will be dismantled and moved to its final underground position next to the CMS experimental cavern.

This paper compiles the commissioning activities starting from the compressor station up to the intermediate cryostat interfacing the refrigerator cold box with the magnet thermosiphon cooling system. It reports the problems encountered and the lessons learned during the commissioning phase and summarizes the results of the refrigeration power measurements in the transient cool-down and the steady-state operation modes.

CERN, Accelerator Technology Department, Geneva, Switzerland

Presented at the CEC-ICMC'05 Conference

29 August-2 September 2005, Keystone, Colorado, USA

Administrative Secretariat

AT Department

CERN

CH - 1211 Geneva 23
Geneva, Switzerland

12 January 2006 


\title{
COMMISSIONING OF THE HELIUM \\ REFRIGERATION SYSTEM FOR THE COMPACT \\ MUON SOLENOID (CMS) DETECTOR OF LHC
}

\author{
G. Perinić and T. Dupont \\ CERN, European Organization for Nuclear Research \\ CH-1211 Geneva 23, Switzerland
}

\begin{abstract}
At CERN a new helium refrigeration plant specified for a cooling capacity of $800 \mathrm{~W}$ at $4.45 \mathrm{~K}, 4500 \mathrm{~W}$ between $60 \mathrm{~K}$ and $80 \mathrm{~K}$ and $4 \mathrm{~g} / \mathrm{s}$ liquefaction simultaneously has been installed and commissioned. In a first operation phase, the plant will provide the refrigeration capacity for the cool down and the operation of the superconducting solenoid of the CMS experiment during the magnet tests at the surface of the LHC interaction point 5. On completion of the tests a part of the refrigeration plant will be dismantled and moved to its final underground position next to the CMS experimental cavern.

This paper compiles the commissioning activities starting from the compressor station up to the intermediate cryostat interfacing the refrigerator cold box with the magnet thermosiphon cooling system. It reports the problems encountered and the lessons learned during the commissioning phase and summarizes the results of the refrigeration power measurements in the transient cool-down and the steady-state operation modes.
\end{abstract}

KEYWORDS: cryogenics, CMS, refrigerator, liquefier, commissioning, PACS: 07.20.Mc

\section{INTRODUCTION}

The CMS (Compact Muon Solenoid) experiment is a general-purpose detector designed to run at the highest luminosity of the proton-proton collisions at the LHC [1]. Distinctive features of the CMS detector include a high-magnetic-field solenoid (4 T) coupled with a multilayer muon system, a fully active scintillating-crystal electromagnetic calorimeter, a tile hadronic calorimeter, and a powerful inner tracking system.

The $220 \mathrm{t}$ cold mass of the high-magnetic-field solenoid will be indirectly cooled by the means of a thermosiphon system. The required cooling power shall be provided by a dedicated helium refrigeration system which has been installed and commissioned in a 


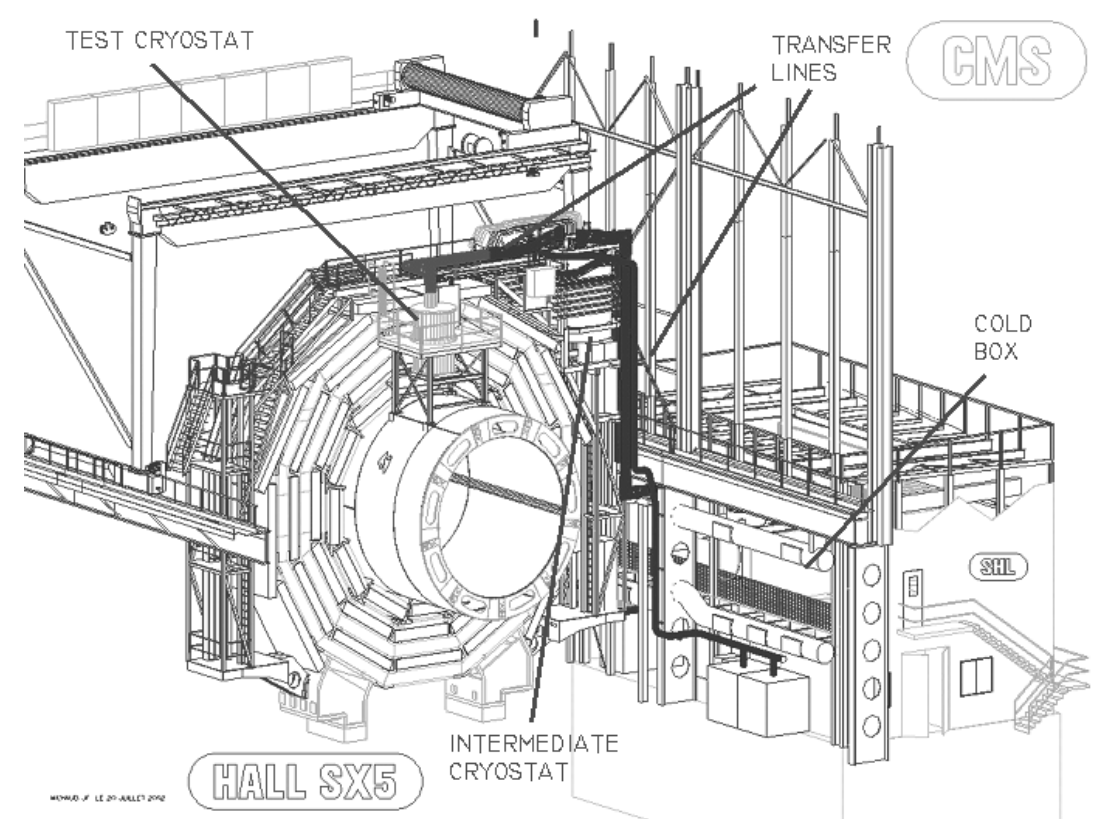

FIGURE 1. Commissioning configuration of helium refrigeration plant in the CMS assembly hall.

temporary position inside the CMS assembly hall. After the full cryogenic test of the solenoid, the cold box will be moved to its final position in the service cavern adjacent to the CMS experimental cavern.

\section{PLANT OVERVIEW}

The helium refrigeration system specification is described in [2,3]. Its refrigeration cycle is based on a modified Claude cycle and it shall provide in the steady state a cooling capacity of $800 \mathrm{~W}$ at $4.45 \mathrm{~K}, 4500 \mathrm{~W}$ between $60 \mathrm{~K}$ and $80 \mathrm{~K}$, and $4 \mathrm{~g} / \mathrm{s}$ liquefaction simultaneously. For the cool down, the refrigeration power is boosted by the means of a $\mathrm{LN}_{2}$ pre-cooler. The helium refrigeration system is subdivided into three major process units: the compressor station, the cold box and the intermediate cryostat. A simplified process flow diagram is shown in FIGURE 3. For the performance tests during the commissioning, these units are complemented by a test cryostat (see FIGURE 2) which allows the simulation of the thermal loads of the magnet in the cool-down mode as well as in the nominal operation mode. The commissioning configuration is shown in FIGURE 1.

All components, but the gaseous helium storage tanks and the control system, have been supplied by Air Liquide (Sassenage, France). Both, the helium storage tanks as well as the control system have been procured in the framework of CERN wide contracts.

\section{COMMISSIONING}

\section{Compressor Station}

The commissioning of the compressor has already been completed in 2002 . However, about one year later, after 500 hours of operation, oil has been found in the third coalescer where normally no visible trace of oil is expected. A measurement revealed that about 3 $\mathrm{ml} / \mathrm{h}$ of compressor oil were accumulating in the third and last coalescer for a helium mass flow of about $756 \mathrm{~kg} / \mathrm{h}$. In order to ensure a sufficiently low oil concentration at the outlet 


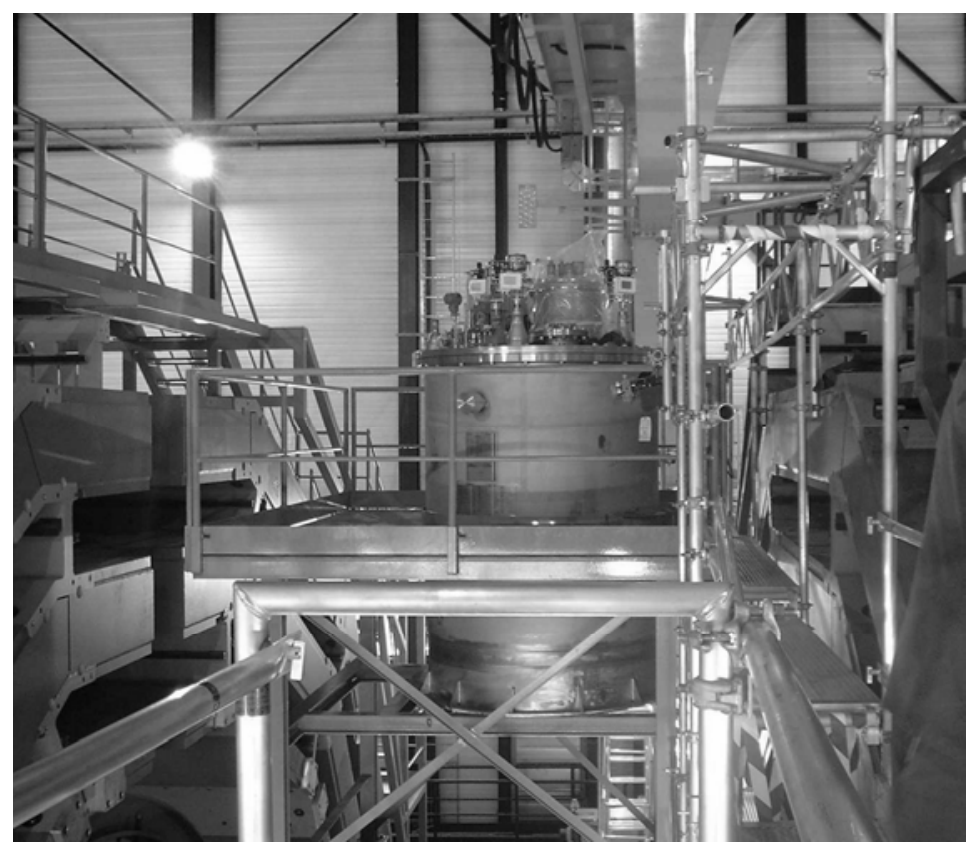

FIGURE 2. Test cryostat located on top of the magnet vacuum vessel.

of the coalescer set it was decided to install an additional coalescer. Unfortunately, very shortly after these modifications a carry-over of oil via the high pressure line to the cold box caused the pollution of the upper cold box circuits. The required cleaning process is described in the cold box section.

Before restarting the cold box a series of measurements has been carried out to help understanding if the oil pollution was due to a steady oil migration or if it had been caused by an accidental coalescer overfill. The overfill had happened a few weeks before the oil was detected in the cold box and it was probably due to the unfortunate combination of a broken level alarm and a faulty automatic purge. The measurements with the original configuration have been compared with measurements in two further configurations. For the measurements we have assumed the bulk oil removal system as a fixed parameter, since a modification would have been time consuming and costly. The results of the measurements are summed up in TABLE 1.

From the measurements it results that the bulk oil removal lets pass more that 530 $\mathrm{ml} / \mathrm{h}$ (or more than $710 \mathrm{ppm}$ ) of oil. This is more than seven times the specified value of $100 \mathrm{ppm}$ and a considerably heavier task for the coalescer set. An additional gravitational

TABLE 1. Oil Removal Efficiency Measurements at $1.8 \mathrm{MPa}$

\begin{tabular}{|c|c|c|c|c|c|}
\hline \multirow[b]{2}{*}{$\begin{array}{l}\text { Original configuration } \\
\text { - oil accumulation }[\mathrm{ml} / \mathrm{h}]\end{array}$} & \multirow{2}{*}{$\begin{array}{c}\text { Bulk oil } \\
\text { removal } \\
6 \times \mathrm{A} 0 \\
\text { not meas. }\end{array}$} & \multicolumn{4}{|c|}{ Coalescers } \\
\hline & & $\begin{array}{c}3 \times \text { A0 } \\
390\end{array}$ & $\begin{array}{c}3 \times \text { AA } \\
270\end{array}$ & $\begin{array}{c}3 \times \text { AA } \\
3\end{array}$ & \\
\hline $\begin{array}{l}\text { Test config. } 1 \text { - with cyclone } \\
\text { - oil accumulation }[\mathrm{ml} / \mathrm{h}] \\
\text { - separation efficiency }\end{array}$ & $\begin{array}{l}6 \times \mathrm{A} 0 \\
960 \\
64 \% \\
\end{array}$ & $\begin{array}{c}\text { Cyclone } \\
60 \\
11 \% \\
\end{array}$ & $\begin{array}{c}3 \times \mathrm{A} 0 \\
330 \\
69 \%\end{array}$ & $\begin{array}{c}3 \times \mathrm{AA} \\
148 \\
99 \%\end{array}$ & $\begin{array}{c}3 \times \mathrm{AX} \\
\text { estim. } 1.5\end{array}$ \\
\hline $\begin{array}{l}\text { Test configuration } 2 \text { - retained } \\
\text { - oil accumulation }[\mathrm{ml} / \mathrm{h}] \\
\text { - separation efficiency } \\
\text { - oil accumul. at } 1 \mathrm{MPa}[\mathrm{ml} / \mathrm{h}]\end{array}$ & $\begin{array}{c}6 \times \mathrm{A} 0 \\
939 \\
63 \% \\
\text { not meas. }\end{array}$ & $\begin{array}{c}3 \times \mathrm{A} 0 \\
342 \\
61 \% \\
\text { not meas. }\end{array}$ & $\begin{array}{l}3 \times \mathrm{AA} \\
221 \\
69 \% \\
230\end{array}$ & $\begin{array}{c}3 \times \mathrm{AA} \\
0.7 \\
99 \% \\
20\end{array}$ & $\begin{array}{c}3 \times \mathrm{AX} \\
\text { estim. } 0.001\end{array}$ \\
\hline
\end{tabular}




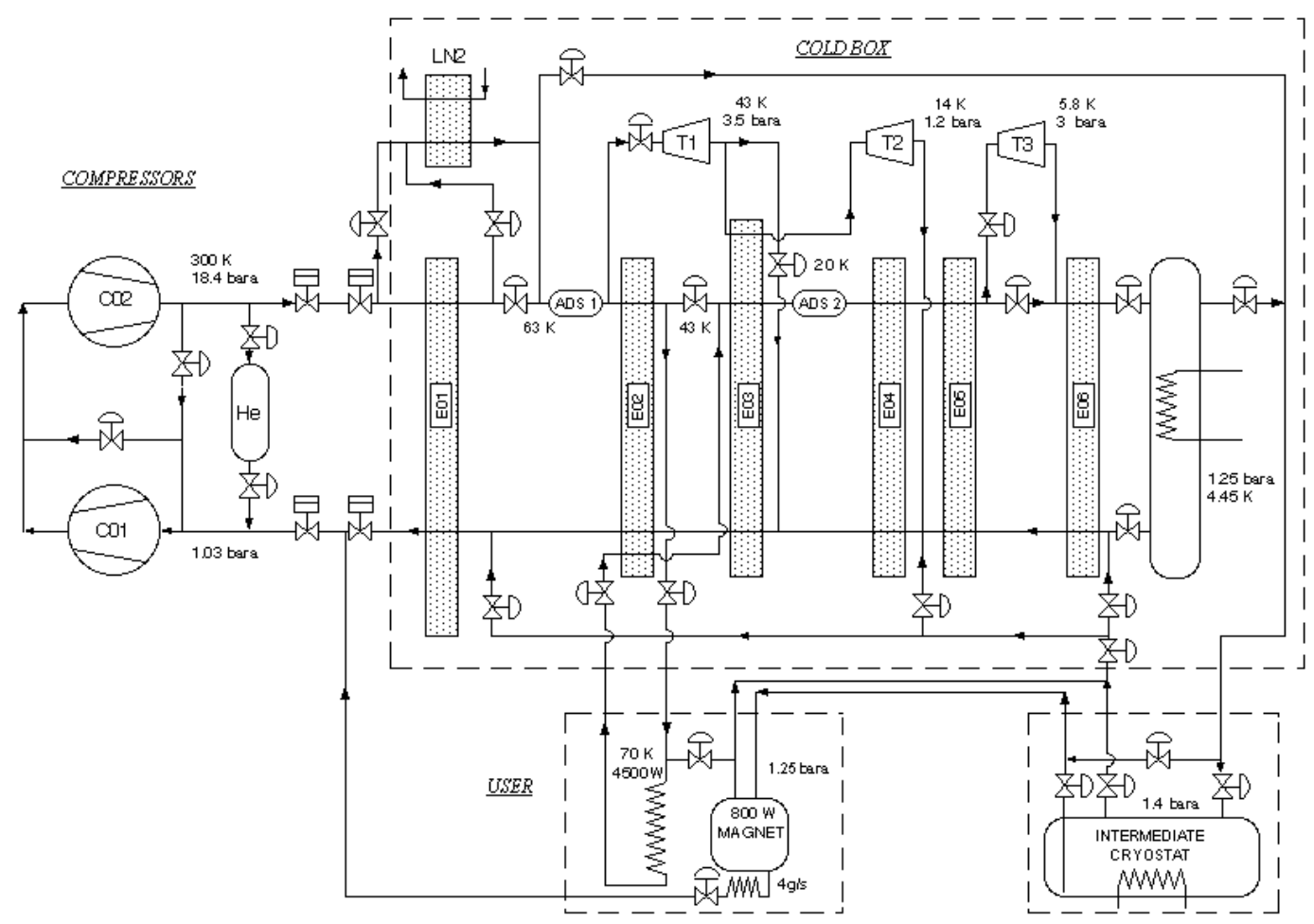

FIGURE 3. Simplified process flow diagram of the CMS refrigeration system.

oil separator (cyclone) in place of the first coalescer did not give satisfactory results as it had an efficiency of only $11 \%$. Therefore, it was decided to retain the original configuration and to add an additional AX type coalescer at the end.

The measurements allow also the conclusion that even in the original configuration the amount of oil reaching the cold box is negligible in the short run. The large pollution with about 1.5 litres of oil must therefore be due to the unfortunate combination of a broken level alarm and a faulty automatic purge that led to the overfilling of one of the coalescers.

A test at a lower compressor pressure indicates that the best oil separation efficiencies are achieved in combination with a specific gas speed. At a pressure of $1 \mathrm{MPa}$ the speed is almost doubled and the amount of oil accumulated in the third coalescer increases significantly.

\section{Cold Box}

The cold box commissioning started in July 2003. During the commissioning period of the cold box we have encountered three major problems besides the typical smaller commissioning issues like defective sensors, errors in the cabling and errors in the control logics.

At first we have had to deal with a starting problem of the third turbine. The particularity of this turbine is being the fact that it has previously only been used on smaller standard refrigeration plants and it took five returns to the supplier's workshop to clear the persistent starting problem.

A few weeks after the modifications of the compressor station oil removal system, a high pressure drop appeared in the pre-cooler heat exchanger. At first moisture was 
suspected and a regeneration at room temperature was carried out. However, the problem appeared again after a few hours and it was decided to inspect the filter of the turbine gas bearing system. In fact the filter contained a few oil droplets and the consequent inspections revealed an oil contamination of the cold box inlet, the cold box high pressure bypass and the transfer lines from the cold box up to the test cryostat.

The oil removal required a thorough cleaning of the affected plant parts by means of isopropyl alcohol. The cleaning was achieved by circulating the alcohol through the polluted circuits in counter flow direction in a closed loop with an external pump. Each time the analysis of the alcohol trespassed a specific limit, the alcohol charge was replaced. Once the cleaning had been accomplished, it turned out to be another challenge to remove about 4001 of alcohol from the lower half of the horizontal main heat exchanger. The circulation of dry nitrogen was not sufficiently effective and the evaporation had to be accelerated by pumping on the heat exchanger with a vacuum pump. In order to avoid explosive mixtures of air and alcohol inside the vacuum pump, a nitrogen cooled trap was used for condensing the alcohol at the pump inlet. In the meantime the compressor station was operated in closed circuit for monitoring the effectiveness of the oil removal system. Once no alcohol was detected any more in the cold trap, the cold box was restarted. The fact that the pressure drop on the pre-cooler heat exchanger appeared again created new worries. However, in this case the regeneration and the evacuation at room temperature revealed the presence of water and solved the problem. We suppose that some moisture that had been dissolved in the alcohol remained in the circuits after the evaporation of the alcohol.

The third major problem of the commissioning was a helium leak inside the cold box that was detected already very early in the commissioning process. As it was just small enough to cope with, the leak detection inside the cold box has only been done after the basic commissioning. The test revealed a leak on the body of one cold valve. The attempt of a repair weld failed possibly due to the very difficult access for the welder to the valve body. As the leak had become larger by the repair attempt, it became inevitable to replace the valve body. For this operation a window had to be cut into the cold box shell.

The commissioning of the cold box has been achieved in March 2005.

\section{Intermediate Cryostat and Test Cryostat}

The intermediate cryostat had already been subject to important delays before the commissioning due to problems with the supplier and an unfortunate accident during installation.

During the first operations with the intermediate cryostat, an excessive pressure drop has been detected on the user side. The analysis carried out by the operators revealed that it was due to the two non-return valves protecting the cryostat against back-pressure from the user. In order to continue the commissioning without delay, it was decided to completely remove the two valves. Like for the valve in the cold box, the access to the non-return valves was difficult as the cryostat vacuum vessel can only be lowered by $80 \mathrm{~cm}$ in the installed position. This meant that the thermal shield could not be removed and it was therefore necessary to cut a hole into the shield in order to access the two valves.

In the test cryostat, the gas heater circuits for the cool-down performance measurements, for the shield load simulation as well as for the current lead simulation worked very reliably. However, the first performance measurements with the heater in the LHe bath simulating the refrigeration power resulted in too low refrigeration power values. Comparing trends with and without the current lead simulation heater in operation revealed 


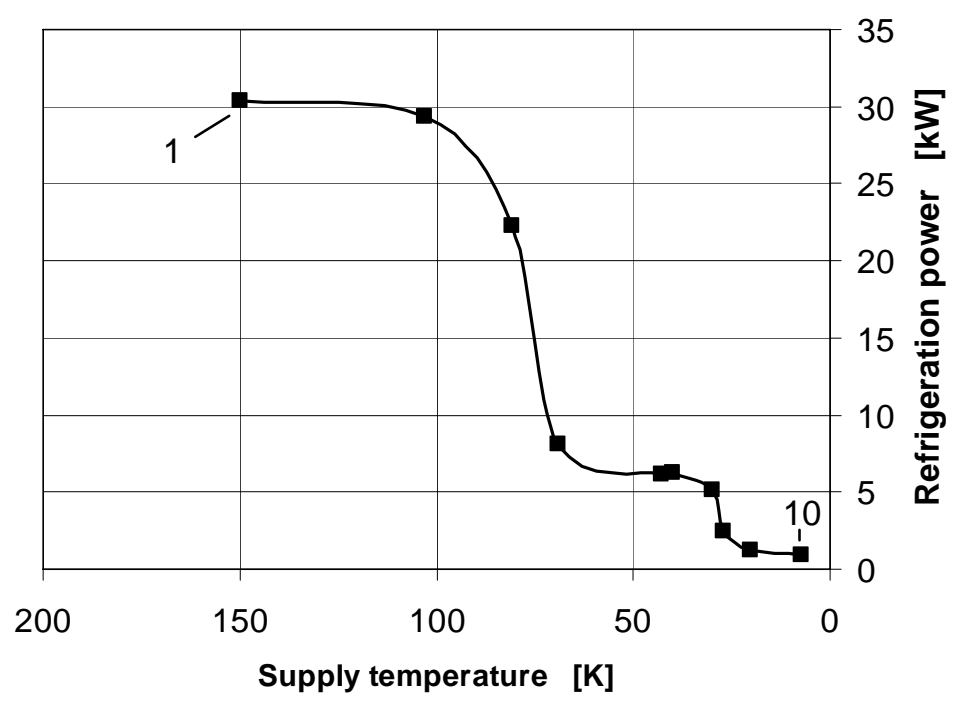

FIGURE 4. Refrigeration power for the cool-down. Refrigeration mode: Points $1,2-\mathrm{LN}_{2}$; Point $3-\mathrm{LN}_{2}$ and Turbines 1 and 2; Points 4-9 - Turbines 1 and 2; Point 10 - Turbines 1, 2 and 3.

that the power applied in this heater influenced the power measurements. It was determined that the $6.5 \mathrm{~kW}$ heater introduced up to $100 \mathrm{~W}$ heat load at the outlet of the test cryostat reservoir. Hence, an alternative solution for simulating the refrigeration power had to be found. This was achieved by transferring the refrigeration power to the intermediate cryostat and to use the bath heaters in there. The necessity to perform reliable measurements required the installation of some additional instrumentation.

\section{Controls}

In March 2005 the original supervision unit has been replaced by PVSS (ETM professional control $\mathrm{GmbH}$ ) in order to replace a system that has been discontinued at CERN and to adapt to the CERN wide cryogenic controls standard. In due course all signals have been re-checked and the plant has been re-tested with the new system.

The upgrade has eliminated a long list of bugs which were linked to the old supervision system. However, it has also introduced a few new problems and unfortunately it has re-introduced some previously solved problems. This was due to the fact that the upgrade installation was done on the basis of a manually updated database rather than using the production database.

In due course of the tests of the various plant components a large number of corrections, modifications and improvements have been integrated on-line.

\section{PERFORMANCE MEASUREMENTS}

The measurement of the compressor station efficiencies is described in [3]. The overall efficiency was measured as $54.6 \%$ for the first stage and $54.4 \%$ for the second stage which yields a compressor efficiency of $56.9 \%$ for the type WLV 321 (Howden compressors Ltd.) first-stage compressor and 56.6\% for the type WLV 204 second-stage compressor when calculating with a motor efficiency of $96 \%$.

The performance of the cold box has been measured in cool-down mode and in nominal operation mode. For the measurements of the cool-down mode performance, the 
TABLE 2. Measured performance at operation conditions

\begin{tabular}{lc}
\hline $\begin{array}{l}\text { Measurement date } \\
15.07 .0518: 00 \mathrm{~h}-18.07 .059: 00 \mathrm{~h}\end{array}$ & mean values and standard deviations \\
\hline Shield power & $4429 \mathrm{~W}(12) @ 43.8 \mathrm{~K}(0.21)-68.9 \mathrm{~K}(0.25)$ \\
Liquefaction rate & $4 \mathrm{~g} / \mathrm{s}(0.02)$ \\
Refrigeration power (in brackets converted to & $952.6 \mathrm{~W}(11.2) @ 0.14 \mathrm{MPa}$ \\
specification conditions) & $(\approx 925.1 \mathrm{~W} @ 0.125 \mathrm{MPa})$ \\
\hline
\end{tabular}

$220 \mathrm{t}$ cold mass has been simulated by a $40 \mathrm{~kW}$ gas heater inside the test cryostat. The measurement points have been chosen in the vicinity of the calculated points from the plant design calculation sheets. The results are plotted in FIGURE 4.

The measurement of the nominal refrigeration and liquefaction power at operation temperature was not straightforward as the first measurements with the test cryostat did not give conclusive results. The analysis of the problem revealed an important thermal leak in between the heater simulating the current leads and the test cryostat return flow. The measurements have therefore been carried out in the following configuration: The shield load heater in the test cryostat was set to $4500 \mathrm{~W}$. The controls of the shield bypass in the cold box ensured a constant temperature difference of $25 \mathrm{~K}$. The flow in the current lead simulation branch was set to $4 \mathrm{~g} / \mathrm{s}$. The current lead simulation heater controlled automatically an outlet temperature of $20{ }^{\circ} \mathrm{C}$. The heater in the intermediate cryostat was set to control the level in the intermediate cryostat at $8 \%$. The maximum available refrigeration power is therefore the power of the intermediate cryostat heater minus $72.4 \mathrm{~W}$ for the evaporation of the $4 \mathrm{~g} / \mathrm{s}$ liquefaction load. The power indication on the intermediate cryostat heater thyristor has been multiplied by 1.0645 , the correction factor which had been determined by prior comparison with a calibrated three-phase power meter. During the measurements a level of $25 \%$ has been maintained in the test cryostat. The average values measured over three days in steady state are listed in TABLE 2.

Due to the fact that a liquid level has been maintained in the test cryostat during the tests, a part of the heat load has been added to the plant losses. From the observation of the test cryostat return temperature during the various tests, it can be estimated that the test cryostat heat load was at least $50 \mathrm{~W}$ in the test configuration.

When combining the shield cooling with the liquefaction and the refrigeration power to an equivalent refrigeration power at $4.45 \mathrm{~K}$ one obtains $1806 \mathrm{~W}$ ( $389 \mathrm{~W}$ shield cooling + $492 \mathrm{~W}$ liquefaction $+925 \mathrm{~W}$ refrigeration). During the measurement the power consumption was $260 \mathrm{KW}$ for the first-stage compressor and $251.6 \mathrm{~kW}$ for the secondstage compressor.

\section{CONCLUSIONS}

For the commissioning quite a number of conclusions can be drawn from the analysis of the fault reports in the commissioning logbook: for one instrumentation and electricity entry there are about 1.8 entries for mechanical issues and 6.2 entries for controls issues. However, if analyzing the required manpower and capital cost for resolving the problems, the situation is very different. The majority of controls issues are solved in less than one hour, only a few take a day and a very few more than a day to be solved. In addition, with a few exceptions, only manpower is required to solve the problems. For instrumentation 
issues very often manpower and hardware is required. Even though the work to solve the problems is usually in the order of hours, the delivery delay and the difficulty to access some instrumentation, e.g. inside the cold box, expands the lifetime of the problems significantly. Fortunately many problems do not interfere with operation as redundancies are installed or workarounds can be found. Mechanical problems, on the other hand, are much more critical as they easily require manpower in the order of days and they are often costly to be solved. The turbine problems, the oil pollution accident and the intermediate cryostat accident, to give the most important examples, account for four to six months of delay each. The observations are comparable with those on the FZK refrigeration plant as described in [4].

The performance measurements have yielded a refrigeration power margin of about $125 \mathrm{~W}$ more than specified. As the measurements have taken into account the test cryostat losses, there is also a margin for the additional transfer line length that will be used in the cavern configuration and for the magnet phase separator.

\section{OUTLOOK}

At present the work for assembling the CMS solenoid is under way. The test cryostat has been removed and the transfer line in between the intermediate cryostat and the test cryostat has been cut back to the point of connection with the magnet thermosiphon phase separator. Furthermore the transfer line in between cold box and intermediate cryostat has been cut and all the cabling to the intermediate cryostat and the test cryostat has been temporarily removed in order to allow the movement of the central barrel of the CMS detector. The central barrel will be moved in order to integrate the solenoid coil and the internal part of the vacuum vessel before it will return into the test position. During this period the controls of the refrigeration system shall be adapted to the magnet operation scenario. Once the transfer line will be re-connected and the cabling will be re-established, the commissioning of the instrumentation on the magnet phase separator will have to be carried out.

The cool-down and test of the magnet is foreseen for the beginning of 2006. After the tests all but the compressor station will be installed in the final position in the service and experimental caverns $90 \mathrm{~m}$ underground.

\section{REFERENCES}

1. Hervé, A. et al., IEEE Trans. Appl. Supercond. 12, pp. 385-390 (2002) no.1.

2. Perinić, G. et al., "The Helium Cryogenic Plant for the CMS Superconducting Magnet," Adv. in Cryog. Eng. 47, edited by S. Breon et al., Am. Inst. of Phys., 2002, pp. 232-238.

3. Perinić, G. et al., IEEE Trans. Appl. Supercond. 14, pp. 1708-1710 (2004) no.2.

4. Perinić, G. "Experience in Four Years Operation of the 2kW-He I-Refrigerator at FZK/Karlsruhe," Adv. in Cryog. Eng. 43, edited by P. Kittel, Plenum Press, 1998, pp. 565-569. 